\title{
ГУМИФИКАЦИЯ ВЕГЕТАТИВНОЙ ЧАСТИ ТОПИНАМБУРА ГРИБАМИ РОДА TRICHODERMA
}

\author{
() М.А. Пикозина, Н.А. Чупрова, Т.В. Рязанова" \\ Сибирский государственный технологический университет, ул. Мира, 82, \\ Красноярск, 660049 (Россия), e-mail: bioleif@yandex.ru
}

\begin{abstract}
В статье представлены результаты исследования гуминовых веществ, выделенных из исходного и биодеструктированного топинамбура. Показано изменение в составе функциональных групп и элементного состава.

Проведенные исследования позволили установить, что в процессе биоконверсии происходят не только количественные, но и качественные изменения препаратов гуминовых веществ.

Ключевые слова: топинамбур, гуминовые вещества, функциональные группы, биоконверсия.
\end{abstract}

\section{Введение}

Гуминовые вещества - это основная органическая составляющая почвы, воды, а также твердых горючих ископаемых. Гуминовые вещества образуются при разложении растительных и животных остатков под действием микроорганизмов и абиотических факторов среды.

Образование гуминовых веществ, или гумификация, - это второй по масштабности процесс превращения органического вещества после фотосинтеза. В результате фотосинтеза ежегодно связывается около $50 \cdot 10^{9}$ т атмосферного углерода, а при отмирании живых организмов на земной поверхности оказывается около $40 \cdot 10^{9}$ т углерода. Часть отмерших остатков минерализуется до $\mathrm{CO}_{2}$ и $\mathrm{H}_{2} \mathrm{O}$, остальное превращается в гуминовые вещества, которые выполняют важную роль в биосфере. Они участвуют в структурообразовании почвы, накоплении питательных элементов и микроэлементов в доступной для растений форме, регулировании геохимических потоков металлов в водных и почвенных экосистемах [1].

Гуминовые вещества - одни из самых сложных по строению природных органических соединений. Это не индивидуальное соединение, а сложная смесь макромолекул переменного состава нерегулярного строения, к которой неприменимы законы классической термодинамики и теории строения вещества [1].

Любые гуминовые вещества содержат большой набор функциональных групп, они полифункциональны. Их молекулы содержат карбоксильные группы - $\mathrm{COOH}$, фенольные -OH, хинонные =C=O, аминогруппы - $\mathrm{NH}_{2}$ и др. Их количество, во-первых, велико, во-вторых, они распределены неравномерно по молекулам различного размера, и даже молекулы одного размера могут различаться по содержанию функциональных групп. Более того, молекулы гуминовых веществ различаются по количеству входящих в их

Пикозина Мария Александровна - аспирантка кафедры химических технологий и биотехнологий, e-mail: bioleif@yandex.ru

Чупрова Нелли Александровна - доцент кафедры химических технологий и биотехнологий, кандидат технических наук

Рязанова Татьяна Васильевна - заведующая кафедрой химической технологии древесины и биотехнологии, доктор технических наук, профессор,

e-mail: tatyana-htd09@mail.ru состав остатков аминокислот (всего их 17-20), по количеству углеводных остатков и характеру их расположения [2].

При различных типах воздействия количество функциональных групп может значительно меняться.

Таким образом, целью данного исследования было изучение влияние процесса биодеструкции на количественный и качественный состав гуминовых веществ.

\footnotetext{
* Автор, с которым следует вести переписку.
} 


\section{Экспериментальная часть}

Гуминовые вещества выделяли из вегетативной части топинамбура до и после биодеструкции его грибами рода Trichoderma штаммами М99/1 и М99/9. Топинамбур - многолетнее травянистое растение высотой около 1,5 м, иногда до 4 м [3]. Вегетативная часть топинамбура представляет собой перспективное сырье для биотехнологической переработки. Это обусловлено богатым полисахаридным составом, необходимым для быстрого и полноценного роста микромицетов. Так, доля веществ углеводной природы в стеблях топинамбура колеблется от 56,5 (июнь) до 69,3\% (апрель) [4]. Кроме того, зеленая часть топинамбура обладает ценным витаминным составом [3]. Таким образом, вегетативная часть - это продуктивная биомасса, обладающая всеми необходимыми для биотехнологической переработки свойствами.

Биодеструкцию проводили методом твердофазного культивирования грибов рода Trichoderma. В подготовленный субстрат вносили посевной материал в расчете $1 \cdot 10^{6}$ спор/г а.с.с. Культивирование проводили в термостате при температуре $27,5-28,5^{\circ} \mathrm{C}$ и начальной влажности субстрата $70-75 \%$. Продолжительность культивирования составила 16 сут.

Гуминовые вещества для исследования выделяли трехкратной обработкой субстрата 0,1 н. $\mathrm{NaOH}$ при комнатной температуре и модуле $1: 10$. К полученному щелочному экстракту прибавляли концентрированную соляную кислоту до достижения $\mathrm{pH}$ 1-2, при этом из раствора выпадал осадок гуминовых кислот, который затем отфильтровывали и высушивали. Полученные порошки черного цвета подвергали дальнейшим исследованиям.

Содержание углерода, водорода, кислорода, азота определялось в образцах гуминовых веществ на анализаторе $\mathrm{CHN}-1$.

ИК-спектры снимали на спектрофотометре в области длин волн 400-4000 $\mathrm{cm}^{-1}$. Приготовление образцов для спектроскопии осуществляли путем прессования препаратов гуминовых веществ совместно с галоидными солями щелочных металлов $(\mathrm{KBr})$ в виде таблеток. Навеска препарата 0,5\% по отношению к мacce $\mathrm{KBr}[5]$.

Поверхностные фенольные группы определяли по методу, основанному на реакции ионного обмена едкого калия с фенольными и карбоксильными группами. Избыток едкого калия титровали соляной кислотой [5].

Карбоксильные группы определяли по методу, в основе которого лежит обмен хемосорбционного типа между кислыми группами вещества и $\left(\mathrm{CH}_{3} \mathrm{COO}\right)_{2} \mathrm{Ca}[5]$.

Алифатические гидроксильные группы определяли методом, основанным на ионном обмене хемосорбционного типа между кислыми группами вещества и $\mathrm{BaC}_{2}$ [5].

\section{Результаты и обсуждение}

Содержание и характеристики гуминовых веществ приведены в таблице.

Как видно из таблицы, биодеструкция вегетативной части топинамбура грибами рода Trichoderma приводит к накоплению гуминовых веществ. Для образца 2 выход гуминовых веществ по сравнению с исходным образцом увеличился в 1,64 раза, для образца 3 - в 1,8 раза. Прирост выхода гуминовых веществ возможен частично за счет деструкции лигноуглеводного комплекса.

Кислые и ионообменные свойства гуминовых веществ зависят от кислородсодержащих функциональных групп. Гуминовые вещества содержат большой набор кислородсодержащих функциональных групп. Наибольшее значение в реакциях органоминерального взаимодействия имеют карбоксильные и фенольные гидроксильные группы.

Содержание и характеристики гуминовых веществ вегетативной части топинамбура

\begin{tabular}{l|c|c|c}
\hline \multirow{2}{*}{ Наименование параметра } & \multicolumn{3}{|c}{ Характеристики гуминовых веществ } \\
\cline { 2 - 4 } & $\begin{array}{c}\text { Исходный } \\
\text { образец (1) }\end{array}$ & $\begin{array}{c}\text { Образец, биодеструктиро- } \\
\text { ванный штаммом М99/1 (2) }\end{array}$ & $\begin{array}{c}\text { Образец, биодеструкти- } \\
\text { рованный штаммом } \\
\text { М99/1 (3) }\end{array}$ \\
\hline Выход гуминовых веществ, \% а.с.с & 5,9 & 9,7 & 10,8 \\
Фенольные гидроксильные группы, \% а.с.н & 0,71 & 0,80 & 0,85 \\
Алифатические гидроксильные группы, \% а.с.н & 3,67 & 4,38 & 4,20 \\
Общие гидроксильные группы, \% а.с.н & 4,38 & 5,18 & 5,05 \\
Карбоксильные группы, \% а.с.н & 6,10 & 5,19 & 5,06 \\
Н,\% & 4,03 & 5,53 & 5,05 \\
С, \% & 49,48 & 49,43 & 50,57 \\
О и азот, \% & 1,3 & 45,04 & 44,98 \\
Н/С & & 1,3 & 1,2 \\
\hline
\end{tabular}


Кислые карбоксильные, фенольные гидроксильные группы гуминовых веществ образуют с катионами металлов связи ионного типа. Это является причиной хорошей диссоциации таких соединений в водных растворах, а следовательно, способствует высокой растворимости гуматов щелочных растворов. Эти же группы играют важную роль и при взаимодействии гуминовых веществ с минералами, в частности при образовании сложных железистых или железофосфатных мостиков между поверхностью частицы глинистого минерала и молекулой гуминовых веществ [5].

Из таблицы видно, что образцы гуминовых веществ содержат большое количество карбоксильных групп. Процесс биоконверсии оказывает значительное влияние на содержание карбоксильных групп в гуминовых веществах. Их содержание снижается для образцов 2 и 3 в 1,2 раза по сравнению с исходным образцом. По-видимому, это можно объяснить протеканием процессов декарбоксилирования.

Фенольные гидроксильные группы содержатся в небольшом количестве (для исходного образца 0,71\%). В процессе биоконверсии происходит незначительное изменение их содержания.

Содержание алифатических групп гуминовых веществ для исходного образца топинамбура составляет 3,67\%. В процессе биоконверсии происходит увеличение их в образце 2 в 1,2 раза и образце 3 в 1,1 раза, что можно объяснить разрывом простых эфирных связей между пропановыми цепочками.

Гуминовые вещества характеризуются неоднородностью химического состава в зависимости от природы, способа выделения. Сведения об элементном составе вещества позволяют получить значительную информацию о строении соединений и их свойствах. В полученных образцах определяли содержание водорода, углерода и кислорода [6].

Наибольшее количество углерода содержится в гуминовых веществах биодеструктированных субстратов. По сравнению с исходным субстратом 1 количество углерода увеличилось для образцов 2 и 3 в 1,1 раза.

Важную информацию о структуре гуминовых веществ несет отношение Н/C, которое указывает на степень насыщенности молекул гуминовых веществ водородом и выражает степень конденсированности структуры. После биодеструкции для образца 2 не происходит заметных изменений, а для образца 3 наблюдается снижение отношения Н/C, что, по-видимому, свидетельствует о повышении степени ароматичности и образовании более конденсированных структур.

Таким образом, процесс биоконверсии вносит ряд определенных изменений в содержание всех функциональных групп исследуемых образцов.

Инфракрасная спектроскопия, являясь одним из наиболее перспективных оптических методов исследования химического строения гуминовых кислот, дает исключительно богатую информацию не только о наборе важнейших атомных групп и типов связей, но и о конкретном расположении их, а также помогает более полно представить строение молекул гуминовых кислот, не нарушая их целостности. ИК-спектры представлены на рисунке.

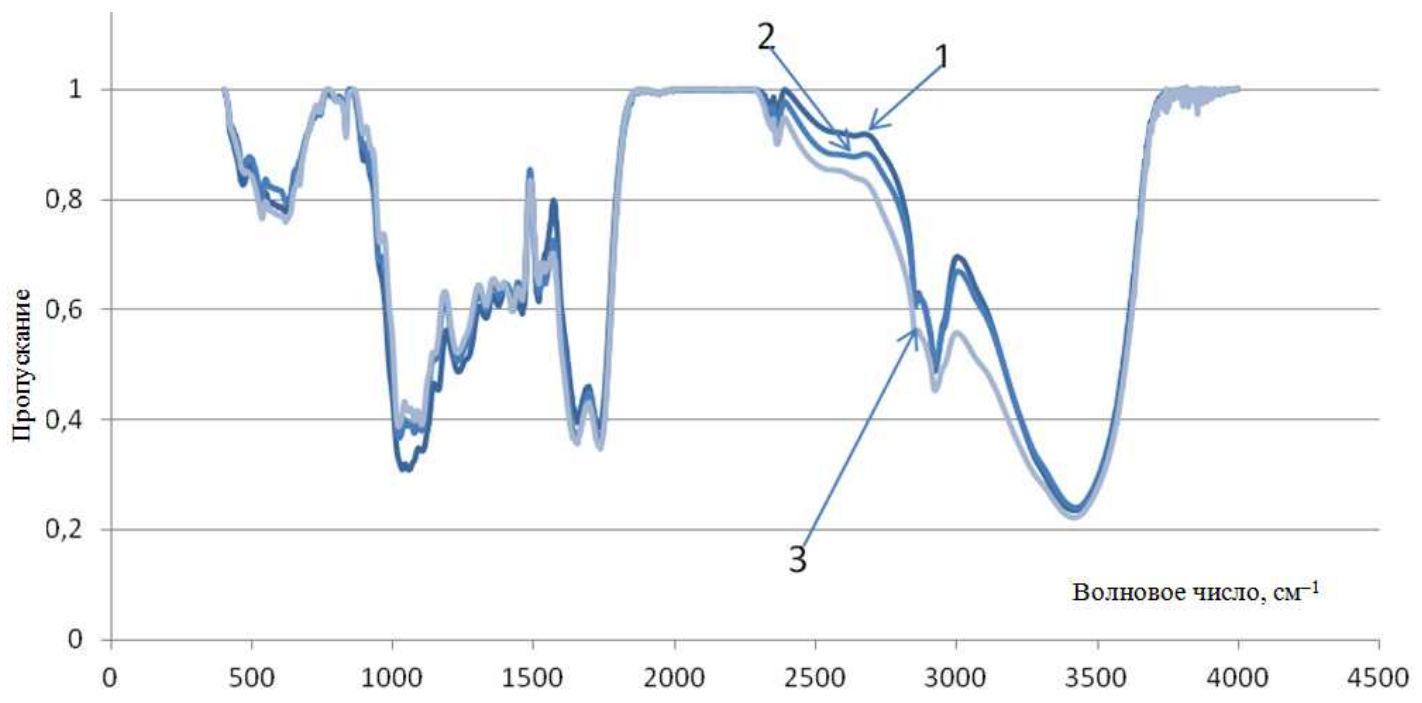

ИК-спектры гуминовых веществ: 1 - образец 1; 2 - образец 2; 3 - образец 3 
Стоит отметить, что ИК-спектры биодеструктированных образцов схожи с исходным образцом. Как видно из рисунка, в полученных образцах в области 3600-3300 см-1 присутствует весьма широкая и интенсивная полоса в препаратах гуминовых веществ, обусловленная валентными колебаниями спиртовых и фенольных гидроксильных групп, преимущественно связанных межмолекулярными водородными связями.

Невысокая интенсивность полос этих групп согласуется с представлениями о малой роли алканов в построении молекул гуминовых веществ, а также с тем, что алифатическая (гидролизуемая) их часть представленаа почти полностью аминокислотами и углеводами.

Гумусовые кислоты в области $1700 \mathrm{~cm}^{-1}$ обладают сильным поглощением. Для гуминовых кислот наиболее характерно положение максимума поглощения при $1720 \mathrm{~cm}^{-1}$ [2]. В исследуемых препаратах гуминовых кислот также наблюдается сильное поглощение в этой области с максимумом при 1717 и $1715 \mathrm{~cm}^{-1}$, которое обусловлено преимущественно карбонильными группами $\mathrm{C}=\mathrm{O}$ карбоновых кислот.

Пики поглощения в области $1660 \mathrm{~cm}^{-1}$ указывают на присутствие хинонных $\mathrm{C}=\mathrm{O}$ групп или $\mathrm{C}=\mathrm{O}$ в алифатических шестичленных циклах. Наблюдаются отдельные полосы в области 1650-1640 см ${ }^{-1}$ и 1550 $1540 \mathrm{~cm}^{-1}$, характерные для амидных групп. Эти полосы свидетельствуют о сохранности в молекулах гуминовых кислот отдельных фрагментов протеинов, а также доказывают наличие карбоксильных и карбонильных групп.

В спектрах гуминовых веществ обнаружена достаточно сильная полоса в области $1625-1610 \mathrm{~cm}^{-1}$. Поглощение в этой области имеет сложное происхождение и обусловлено в основном влиянием $\mathrm{C}=\mathrm{C}$ связей бензоидных структур (ароматических), содержащих полярные заместители, $\mathrm{C}=\mathrm{O}$ карбонилов, связанных водородной связью, хиноны, также связанные с группами ОН водородной связью.

Поглощение в области 1260-1200 см-1 можно приписать деформационным колебаниям атомов карбоксильной группы.

Четко выявляются полосы деформационных колебаний ОН-спиртовых групп при 1150-1050 $\mathrm{cm}^{-1} \mathrm{y}^{-1}$ всех представленных образцов.

При сравнении биодеструктированных образцов с исходным можно выделить широкие области, в которых спектры полностью совпадают (4000-3500, 2300-1700, 900-689 см${ }^{-1}$ ).

Кроме того, весь спектр образца, биодеструктированного штаммом М99/9, на всей области волновых чисел наименее интенсивен как в сравнении с образцом, биодеструктированным штаммом М99/1, так и с исходным образцом.

\section{Выводы}

Исследования гуминовых кислот показали, что процесс биодеструкции вегетативной части топинамбура грибами рода Trichoderma приводит к гумификации, т.е. накоплению гуминовых веществ в полученном биопрепарате, что положительно отразится на его свойствах.

Кроме того, гуминовые кислоты содержат большой набор кислородсодержащих функциональных групп: карбоксильные, фенольные, алифатические. Данные, полученные экспериментально и с помощью ИК-спектроскопии, хорошо согласуются между собой и указывают на то, что максимальное содержание кислотных функциональных групп приходится на образцы, подвергавшиеся биодеструкции, что может свидетельствовать о более высокой реакционной способности данных гуминовых кислот.

\section{Список литературы}

1. Перминова И.В. Гуминовые вещества - вызов химикам ХХІ века // Химия и жизнь. 2008. №1. С. 125-133.

2. Орлов Д.С. Гуминовые вещества в биосфере. М., 1990. 325 с.

3. Эйхе Э.П. Вопросы химии и биохимии топинамбура. М., 1976. 189 с.

4. Рязанова Т.В. Химический состав вегетативной части топинамбура и ее использование // Известия вузов. Лесной журнал. 1997. №4. С. 71-75.

5. Закис Г.Ф., Можейко Л.Н., Телышева Г.М. Методы определения функциональных групп лигнина. Рига, 1975. $176 \mathrm{c}$.

6. Иванов А.А., Юдина Н.В., Ильина А.А. Кислотные и ионообменные свойства гуминовых кислот механоактивированных торфов // Химия растительного сырья. 2010. №4. С. 145-150.

Поступило в редакиию 3 августа 2012 г. 
Pikozina M.A., Chuprova N.A., Ryazanova T.V. ${ }^{*}$ HUMIFICATION OF VEGETATIVE PART OF TOPINAMBUR MUSHROOMS TRICHODERMA

Siberian State Technological University, Mira st., 82, Krasnoyarsk, 660049 (Russia), e-mail: bioleif@yandex.ru

The paper presents the results of the study of humic substances which have been before and of the biodestruktion. It was shown the change the elemental composition and functional groups.

Studies have revealed that in the process of bioconversion occur not only quantitative but also qualitative changes of the preparation of humic substances.

Keyword: artichoke, humic substances, functional groups.

\section{References}

1. Perminova I.V. Khimiia i zhizn', 2008, no. 1, pp. 125-133. (in Russ.).

2. Orlov D.S. Guminovye veshchestva v biosfere. [Humic substances in the biosphere]. Moscow, 1990, 325 p. (in Russ.).

3. Eikhe E.P. Voprosy khimii $i$ biokhimii topinambura. [Questions of chemistry and biochemistry of Jerusalem artichoke]. Moscow, 1976, 189 p. (in Russ.).

4. Riazanova T.V. Izvestiia vuzov. Lesnoi zhurnal, 1997, no. 4, pp. 71-75. (in Russ.).

5. Zakis G.F., Mozheiko L.N., Telysheva G.M. Metody opredeleniia funktsional'nykh grupp lignina. [Methods for the determination of the functional groups of lignin.]. Riga, 1975, 176 p. (in Russ.).

6. Ivanov A.A., Iudina N.V., Il'ina A.A. Khimiia rastitel'nogo syr'ia, 2010, no. 4, pp. 145-150. (in Russ.).

Received August 3, 2012

\footnotetext{
"Corresponding author.
} 
